\title{
Serum and erythrocyte folate status of New Zealand women of childbearing age following a countrywide voluntary programme by the baking industry to fortify bread with folic acid
}

\author{
Kathryn E Bradbury ${ }^{1, *} \dagger$, Sheila M Williams ${ }^{2}$, Jim I Mann ${ }^{1}$, Indrawati Oey ${ }^{3}$, \\ Cindy Aitchison ${ }^{1}$, Winsome Parnell ${ }^{1}$, Liz Fleming ${ }^{1}$, Rachel C Brown ${ }^{1}$ and C Murray Skeaff ${ }^{1}$ \\ 'Department of Human Nutrition, University of Otago, Dunedin, New Zealand: ${ }^{2}$ Department of Preventive and \\ Social Medicine, University of Otago, Dunedin, New Zealand: ${ }^{3}$ Department of Food Science, University of Otago, \\ Dunedin, New Zealand
}

Submitted 14 September 2015: Final revision received 9 April 2016: Accepted 14 April 2016: First published online 7 June 2016

\begin{abstract}
Objective: To estimate the folate status of New Zealand women of childbearing age following the introduction, in 2010, of a new voluntary folic acid fortification of bread programme.

Design: The 2011 Folate and Women's Health Survey was a cross-sectional survey of women aged 18-44 years carried out in 2011. The survey used a stratified random sampling technique with the Electoral Roll as the sampling frame. Women were asked about consumption of folic-acid-fortified breads and breakfast cereals in a telephone interview. During a clinic visit, blood was collected for serum and erythrocyte folate measurement by microbiological assay.

Setting: A North Island (Wellington) and South Island (Dunedin) city centre in New Zealand.

Subjects: Two hundred and eighty-eight women, of whom 278 completed a clinic visit.

Results: Geometric mean serum and erythrocyte folate concentrations were $30 \mathrm{nmol} / \mathrm{l}$ and $996 \mathrm{nmol} / \mathrm{l}$, respectively. Folate status was 30-40\% higher compared with women of childbearing age sampled as part of a national survey in $2008 / 09$, prior to the introduction of the voluntary folic acid bread fortification programme. In the 2011 Folate and Women's Health Survey, reported consumption of fortified bread and fortified breakfast cereal in the past week was associated with $25 \%(P=0.01)$ and $15 \%(P=0.04)$ higher serum folate concentrations, respectively.

Conclusions: Serum and erythrocyte folate concentrations have increased in New Zealand women of childbearing age since the number of folic-acid-fortified breads was increased voluntarily in 2010. Consumption of fortified breads and breakfast cereals was associated with a higher folate status.
\end{abstract}

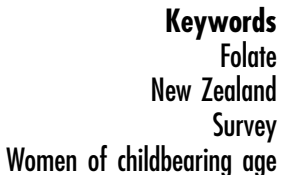

To help reduce the rate of neural tube defects in New Zealand, folic acid fortification of certain food categories, including bread and breakfast cereals, has been permitted but not mandated since 1996. Under these voluntary permissions, a number of breakfast cereals, but few breads, were fortified with folic acid ${ }^{(1)}$. In 2007, the governments of New Zealand and Australia adopted joint legislation that required, at the end of a two-year transition period, all bread to be fortified with folic acid ${ }^{(2,3)}$. However, in August 2009, one month prior to the planned

$†$ Correspondence address: Cancer Epidemiology Unit, Nuffield Department of Population Health, University of Oxford, Richard Doll Building, Old Road Campus, Roosevelt Drive, Oxford OX3 7LF, UK. full implementation of the programme, the New Zealand Government deferred mandatory fortification until May 2012 and, instead, encouraged the bread-baking industry to adopt more extensive voluntary fortification. The four major bread manufacturers in New Zealand, who together produce an estimated $90 \%$ of all bread in the country ${ }^{(4)}$, agreed to add folic acid - at a target of $200 \mu \mathrm{g}$ folic acid per $100 \mathrm{~g}$ of bread - to approximately $30 \%$ of their range of breads by May $2010^{(5)}$.

Arguably the most important part of assessing the effectiveness of any folic acid fortification programme is to monitor its impact on the incidence rate of neural tube defects; however, this is problematic in New Zealand in 
the short term because the annual number of cases is small $^{(1)}$ and reliable documentation of a change in rates may require up to a decade. Furthermore, there is no mandatory requirement to record neural tube defects in terminated pregnancies. Thus total incidence rates are underestimated. A complementary approach is to monitor the blood folate status of women of childbearing age before and after implementation of a fortification programme. For this purpose, the New Zealand Ministry of Primary Industries commissioned a survey (the 2011 Folate and Women's Health Survey) to monitor the blood folate status of women of childbearing age after full implementation of the voluntary programme (May 2010). Change in folate status before and after voluntary fortification could be assessed by using as a baseline the results from the 2008/09 New Zealand Adult Nutrition Survey which included information on the serum and erythrocyte folate concentrations of the New Zealand population $^{(6)}$.

The objective of the 2011 Folate and Women's Health Survey was to estimate the folate status of New Zealand women of childbearing age following the introduction of the new (2010) voluntary folic acid fortification of bread programme. In addition, we examined the influence of the consumption of folic-acid-fortified bread and other folic-acid-fortified foods on blood folate status.

\section{Methods}

\section{Survey design}

The 2011 Folate and Women's Health Survey was a crosssectional survey of women of childbearing age (18-44 years) carried out from April to August 2011 in two city centres of New Zealand: a South Island centre, Dunedin, and a North Island centre, Wellington. We had previously shown that 12 months is sufficient time for serum and erythrocyte folate concentrations to reach a new steady state after a sustained increase in folic acid intake ${ }^{(7)}$, thus we began recruitment for the 2011 Folate and Women's Health Survey in April 2011. The survey was conducted according to the guidelines laid down in the Declaration of Helsinki and all procedures involving human subjects were approved by the University of Otago's human ethics committee. Written informed consent was obtained from all subjects. The survey was registered with the Australia New Zealand Clinical Trials Registry (ACTRN12611000463976). The 2008/09 New Zealand Adult Nutrition Survey was a nationwide multistage random survey of New Zealanders aged 15 years and older. A detailed description of the methods can be found elsewhere ${ }^{(8)}$. For the current paper we include only the results for women between the age of 18 and 44 years in order to match the ages of women who were recruited for the 2011 Folate and Women's Health Survey.
The 2011 Folate and Women's Health Survey used a stratified random sampling technique with the New Zealand Parliamentary Electoral Roll as the sampling frame. All New Zealand citizens and permanent residents aged 18 years or older are required by law to enrol to be registered on the Parliamentary Electoral Roll. Women listed on the electoral roll residing within the local authority boundary of Dunedin city (Dunedin centre) or Wellington city, Porirua city and Hutt city (Wellington centre) were stratified by age (18-19 years; 20-24 years; 25-29 years; 30-34 years; 35-39 years; and 40-44 years). The proportion of women randomly selected from each stratum was based on the proportion of New Zealand women in each of the age categories in the 2006 census $^{(9)}$. The aim was to recruit 300 women in total, 150 from each of the centres, assuming a $50 \%$ response rate.

Recruitment was carried out in the South Island centre (Dunedin) between April and June 2011 and in the North Island centre (Wellington) between June and August 2011. Recruitment followed the four-stage tailored method as recommended by Dillman et al. ${ }^{(10)}$, which involved: (i) an initial postal invitation to participate in the survey, a consent form and a general questionnaire; (ii) 7-8d later a reminder/thank you postcard; (iii) $16 \mathrm{~d}$ after the initial mail-out a second invitation pack; and (iv) $28 \mathrm{~d}$ after the initial mail-out the telephone numbers of the nonrespondents were obtained from the New Zealand White Pages and they were telephoned to invite them to participate one final time. If their number was not listed, or if they were unable to be reached, a final reminder postcard was sent. Due to a lower than anticipated response rate in the sample selected from the Wellington region, a second sample was selected from the Wellington region and contacted following the same procedures described above, with the aim to recruit 150 women in total from Wellington.

The self-administered general questionnaire was used to collect information on the following sociodemographic characteristics: birth date, ethnicity, education level and household income level. The general questionnaire also collected information on factors that may affect folate status including health status, medical conditions, medication use, alcohol and coffee use, smoking status and past pregnancies.

Participants also completed a telephone interview during which information about the specific brands of breakfast cereals, breads and fortified spreads consumed over the past week was collected. Participants were at home when interviewed and were asked to read out the brand name of the packets of breakfast cereals and breads, if available, that they had consumed in the past week. The same was done with dietary supplements. The ingredients lists on packets of breads, breakfast cereals and supplements that were reported by the participants were checked at a supermarket in the local area of the participant for the presence of added folic acid. We classified 
bread as folic acid fortified if the ingredient list stated the bread contained folic acid or folate. Participant responses to the questions were recorded directly on a standardised form. Participants who ate bread outside their house, for instance at a café, were asked to name the café and describe the bread. Where possible, these eateries were contacted and questioned about the brand of breads they used or the brand of ingredients if they made their own bread, to try to identify whether or not the bread consumed by the participant contained folic acid. If this was unable to be identified, the fortification status of the bread was specified as unknown. The telephone interview was typically completed one week before the clinic visit. Information from the general questionnaire and the phone interview was double-entered by K.E.B. and C.A.; discrepancies were investigated and resolved by K.E.B.

Participants were asked to fast overnight before attending a morning clinic. During the clinic visit, height and weight were measured using standardised techniques. Participants were lightly clothed and were not wearing shoes. Blood was taken from an antecubital vein into a $6 \mathrm{ml}$ tube containing EDTA and a $6 \mathrm{ml}$ tube that did not contain anticoagulant. The tube without anticoagulant was left for $1 \mathrm{~h}$ at room temperature before it was centrifuged at $1650 \mathrm{~g}$ for $15 \mathrm{~min}$ at $4^{\circ} \mathrm{C}$ to isolate serum. After the blood draw, the EDTA tubes were placed immediately in a polystyrene container with an ice pack or in a refrigerator. Haematocrit was analysed from whole blood. The whole blood and serum samples were dispensed into aliquots and stored at $-80^{\circ} \mathrm{C}$ within $3 \mathrm{~h}$ of blood collection.

\section{Laboratory metbods}

For both the 2008/09 New Zealand Adult Nutrition Survey and the 2011 Folate and Women's Health Survey, serum and whole-blood folate was measured in the same laboratory by microbiological assay with the use of the test organism Lactobacillus rbamnosus, as described by O'Broin and Kelleher ${ }^{(11)}$. For the 2011 Folate and Women's Health Survey folate analysis began and was completed in November 2011. Samples to be assayed were thawed just prior to use. Immediately after thawing, whole blood was first diluted 1:10 in $1 \%(\mathrm{w} / \mathrm{v})$ ascorbic acid and incubated at $37^{\circ} \mathrm{C}$ for $30 \mathrm{~min}$, then further diluted $1: 40$ in $0.5 \%(\mathrm{w} / \mathrm{v})$ sodium ascorbate. Serum was diluted $1: 20$ in $0.5 \%(\mathrm{w} / \mathrm{v})$ sodium ascorbate. Increasing amounts of folic acid $(200 \mathrm{pg} / \mathrm{ml})$ were used for the standard curve; one standard curve was constructed per day. Plates were incubated for $42 \mathrm{~h}$ at $37^{\circ} \mathrm{C}$ and then read on a microplate reader (Asys UVM 340; Biochrom, Cambridge, UK) with the wavelength set at $590 \mathrm{~nm}$. Linear interpolation was used to generate the standard curve.

The accuracy of the microbiological assay was determined with the use of the NIST (National Institute of Standards and Technology) SRM (Standard Reference Material) 1955 (Homocysteine and Folate in Frozen Human Serum) that was assayed in duplicate on one plate per day. The precision of the assay was monitored by analysing pooled plasma in duplicate on every plate. The analysed values ( $n$ 19) of the three-level NIST SRM 1955 from the 2008/09 New Zealand Adult Nutrition Survey folate analysis were $6.2 \mathrm{nmol} / \mathrm{l}$ (uncertainty range: 4.9 $6 \cdot 3 \mathrm{nmol} / \mathrm{l}$ ), $14.0 \mathrm{nmol} / \mathrm{l}$ (uncertainty range: $12-16 \mathrm{nmol} / \mathrm{l}$ ) and $47 \cdot 1 \mathrm{nmol} / 1$ (uncertainty range: $37-51 \mathrm{nmol} / \mathrm{l}$ ), with CV of $9.8 \%, 12.5 \%$ and $8.9 \%$, respectively. The mean (CV) for the pooled plasma ( $n$ 164) was $19.2 \mathrm{nmol} / \mathrm{l}(16.5 \%)$. The analysed values ( $n$ 4) of the three-level NIST SRM 1955 from the 2011 Folate and Women's Health Survey folate analysis were $7.5 \mathrm{nmol} / 1,15.6 \mathrm{nmol} / 1$ and $48.9 \mathrm{nmol} / 1$, with $\mathrm{CV}$ of $2.4 \%, 3.0 \%$ and $4.3 \%$, respectively. The mean (CV) for the pooled plasma ( $n$ 29) was $19.2 \mathrm{nmol} / \mathrm{l}(12.3 \%)$.

We used a cut-off of less than $6.8 \mathrm{nmol} / 1$ to indicate low serum folate concentrations and an erythrocyte folate concentration of less than $305 \mathrm{nmol} / 1$ to indicate deficiency $^{(12-14)}$.

\section{Statistical analysis}

All statistical analyses were carried out using the statistical software package STATA release 11 . We used multiple linear regression analysis to examine the relationship between blood folate status and dietary variables in the 2011 Folate and Women's Health Survey. Because of their positive skew, serum and erythrocyte folate concentrations were log-transformed before statistical analysis and the differences between groups were presented as ratios. For the 2008/09 New Zealand Adult Nutrition Survey, survey commands were used to take into account the specific design of the survey. Survey weights based on the prioritised ethnicity of those who gave blood samples were used to set the survey design in STATA $^{(8)}$. A two-sided Student's $t$ test for unpaired samples was used to test significant differences in blood folate status between females aged 18-44 years from the 2008/09 New Zealand Adult Nutrition Survey and the 2011 Folate and Women's Health Survey.

\section{Results}

The final weighted response rate of the 2008/09 New Zealand Adult Nutrition Survey for all participants (15 years and older) was $61 \%$. The flow of participants through the 2011 Folate and Women's Health Survey is shown in Fig. 1. Invitations to participate in the study were delivered to 724 women. In total, 296 women consented to participate; of these, eight completed neither a telephone interview nor a clinic visit, leaving 288 included in the analysis. Of these 288 participants, 285 completed a telephone interview and 278 completed a clinic visit. There were ninety-seven participants who declined to take part, fifty-seven non-deliveries of the information packs (i.e. returned to sender) and one woman who was ineligible because she did not understand English. 


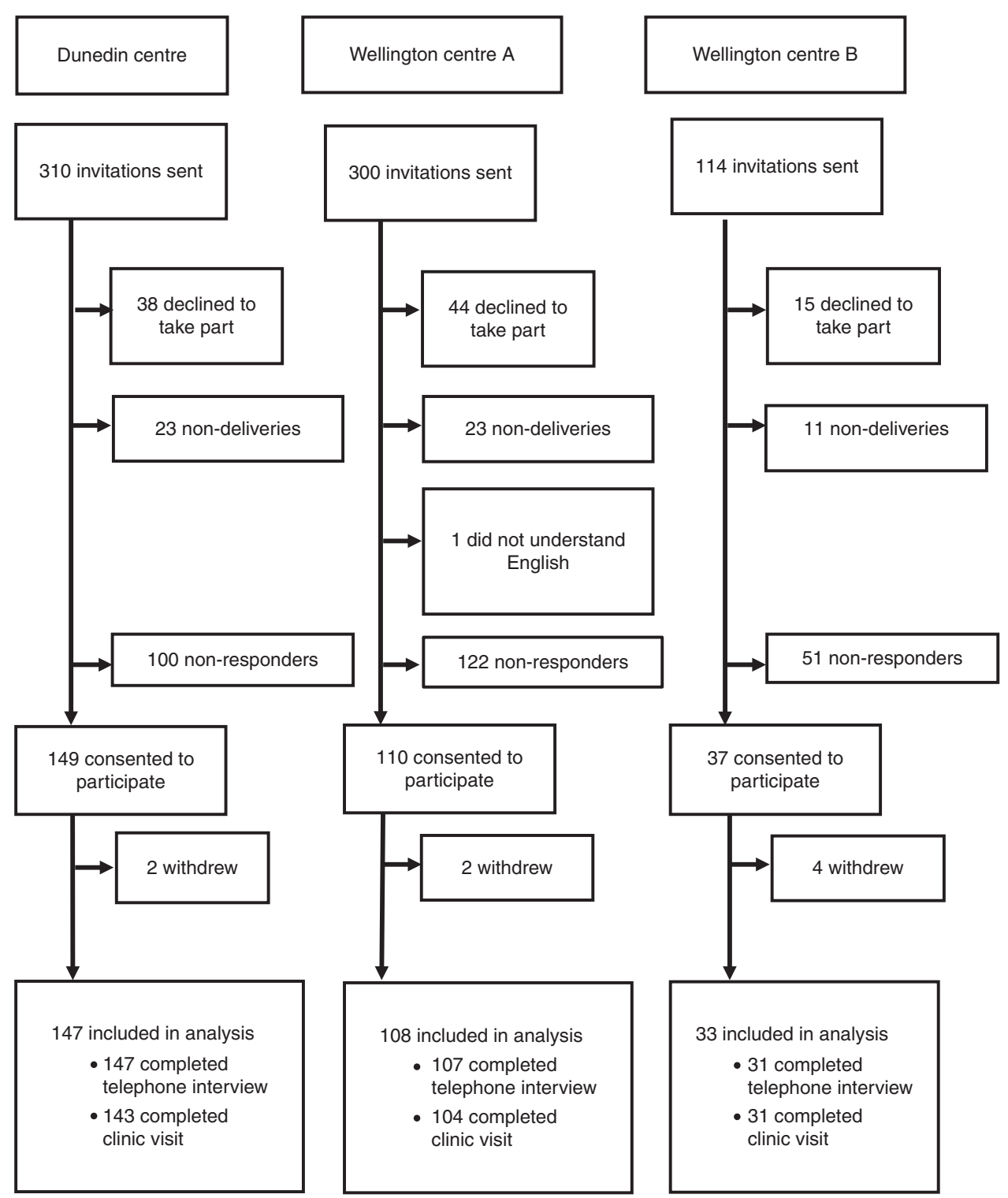

Fig. 1 The flow of participants through the 2011 Folate and Women's Health Survey

Two hundred and seventy-three participants did not respond to the invitation.

The overall response rate of the 2011 Folate and Women's Health Survey was $43 \%$ (participants who completed a telephone interview or clinic visit/[total selected - (non-deliveries + ineligible)], 288/(724-58)). The overall contact rate of the 2011 Folate and Women's Health Survey was 59\% (those contacted (included in analysis + total refused) as a percentage of those eligible (included in analysis + total refused + non-contact)). Non-contacts and refusals accounted for $72 \%$ and $28 \%$ of the overall non-response, respectively.

Characteristics of the female participants aged between 18 and 44 years from the 2008/09 New Zealand Adult Nutrition Survey and the participants of the 2011 Folate and Women's Health Survey are shown in Table 1. These groups were similar in BMI and age. However, more participants of the 2011 Folate and Women's Health Survey were of New Zealand European or other ethnicity and a higher proportion were from less deprived areas.

One per cent of participants in the 2011 Folate and Women's Health Survey had low serum folate concentrations (less than $6.8 \mathrm{nmol} / \mathrm{l}$ ); likewise, $1 \%$ had low erythrocyte folate concentrations (less than $305 \mathrm{nmol} / \mathrm{l}$ ). The geometric mean serum folate concentration was 31\% (95\% CI 19\%, 45\%) higher in women in the 2011 Folate and Women's Health Survey compared with women of the same age range in the 2008/09 New Zealand Adult Nutrition Survey. Similarly, the geometric mean erythrocyte folate concentration was 38\% (95\% CI 29\%, 48\%) higher in women in the 2011 Folate and Women's Health Survey compared with women of the same age range in the 2008/09 New Zealand Adult Nutrition Survey (Table 2). 
Of the 285 participants in the 2011 Folate and Women's Health Survey who completed a telephone interview, 93\% ( $n$ 266) and $72 \%$ ( $n$ 205) reported consuming bread and breakfast cereal in the past week, respectively (Table 3). Among the 285 participants, mean consumption of bread and breakfast cereal was 12 (SD 9) slices and 3.4 (SD 2.8) bowls per week, respectively (data not shown). In the past week, only $18 \%$ ( $n$ 51) of participants could be identified as having consumed at least one slice of bread that was

Table 1 A comparison of the characteristics of participants in the 2008/09 New Zealand Adult Nutrition Survey and the 2011 Folate and Women's Health Survey

\begin{tabular}{|c|c|c|}
\hline & $\begin{array}{c}\text { 2008/09 New Zealand } \\
\text { Adult Nutrition Survey } \\
\text { ( } n \text { 663) }\end{array}$ & $\begin{array}{l}2011 \text { Folate and } \\
\text { Women's Health } \\
\text { Survey ( } n \text { 288) }\end{array}$ \\
\hline & $\%$ & $\%$ \\
\hline BMI $\left(\mathrm{kg} / \mathrm{m}^{2}\right)$, mean & 27 & 27 \\
\hline $\mathrm{SD}$ & 9 & 6 \\
\hline Age (years), mean & 32 & 33 \\
\hline SD & 11 & 8 \\
\hline \multicolumn{3}{|l|}{ Age category } \\
\hline $18-19$ years & 7 & 7 \\
\hline $20-24$ years & 16 & 14 \\
\hline $25-29$ years & 17 & 11 \\
\hline $30-34$ years & 19 & 19 \\
\hline $35-39$ years & 19 & 23 \\
\hline $40-44$ years & 22 & 26 \\
\hline \multicolumn{3}{|l|}{ Ethnicity } \\
\hline NZEO & 78 & 87 \\
\hline Maori & 16 & 9 \\
\hline Pacific & 6 & 4 \\
\hline \multicolumn{3}{|l|}{ NZDep2006 score* } \\
\hline 1 & 5 & 19 \\
\hline 2 & 8 & 9 \\
\hline 3 & 8 & 14 \\
\hline 4 & 12 & 11 \\
\hline 5 & 9 & 9 \\
\hline 6 & 15 & 12 \\
\hline 7 & 11 & 7 \\
\hline 8 & 12 & 6 \\
\hline 9 & 9 & 8 \\
\hline 10 & 12 & 7 \\
\hline
\end{tabular}

NZEO, New Zealand European and others; NZDep2006, 2006 New Zealand Index of Deprivation.

${ }^{*}$ An NZDep2006 score of 1 represents a geographic area with the least deprivation. folic acid fortified, $62 \%$ ( $n$ 177) could be identified as having consumed only non-fortified bread; the remaining bread consumers, $13 \%$ ( $n$ 38), consumed at least one slice of bread of unknown fortificant status (because they did not know the brand of bread eaten). In the past week, $41 \%$ ( $n$ 116) of participants could be identified as having consumed at least one bowl of breakfast cereal that was confirmed as folic acid fortified, $26 \%(n 74)$ could be identified as having consumed only non-fortified breakfast cereal; the remaining consumers, $5 \%$ ( $n$ 15), consumed at least one bowl of breakfast cereal of unknown fortificant status (because they did not know the brand of cereal eaten). Fifty-three per cent reported consuming a folicacid-fortified yeast extract spread in the past week. Twenty-seven per cent of participants reported the consumption of a folate-containing supplement.

The relationship between folic-acid-fortified bread and breakfast cereal consumption and serum and erythrocyte folate concentrations in the 2011 Folate and Women's Health Survey is shown in Table 4. After adjustment for use of folate-containing supplements, recruitment centre and fortified breakfast cereal consumption, participants whom we were able to confirm consumed folicacid-fortified bread in the past week had significantly higher serum folate concentrations than participants who consumed either no bread, or only non-fortified or unidentified bread (adjusted ratio of the geometric means: $1.25(95 \%$ CI $1.05,1.48, P=0.012))$. Erythrocyte folate concentrations were not significantly different between these two groups (adjusted ratio of the geometric means: 1.13 (95\% CI 0.99, 1.28, $P=0.079)$ ). After adjustment for use of folate-containing supplements, recruitment centre and fortified bread consumption, participants whom we were able to confirm consumed folic-acid-fortified breakfast cereal in the past week had significantly higher serum and erythrocyte folate concentrations than participants who consumed either no breakfast cereal, or only nonfortified or unidentified breakfast cereal (for serum folate, adjusted ratio of the geometric means: $1 \cdot 15$ (95\% CI 1.01, $1.31, P=0.042)$; for erythrocyte folate, adjusted ratio of the geometric means: 1.13 (95\% CI 1.02, 1.25, $P=0.019)$ ).

Table 2 A comparison of the folate status of the 2008/09 New Zealand Adult Nutrition Survey participants and the 2011 Folate and Women's Health Survey participants

\begin{tabular}{|c|c|c|c|c|c|c|c|c|c|}
\hline & \multicolumn{2}{|c|}{$\begin{array}{c}\text { 2008/09 New Zealand Adult } \\
\text { Nutrition Survey }\end{array}$} & \multicolumn{2}{|c|}{$\begin{array}{l}2011 \text { Folate and Women's } \\
\text { Health Survey }\end{array}$} & \multicolumn{2}{|c|}{ Mean difference } & \multirow[b]{2}{*}{ Ratio* } & \multirow[b]{2}{*}{$95 \% \mathrm{Cl}$} & \multirow[b]{2}{*}{$P$ value } \\
\hline & Mean & SEM or $95 \% \mathrm{Cl}$ & Mean & SEM or $95 \% \mathrm{Cl}$ & Mean & $95 \% \mathrm{Cl}$ & & & \\
\hline \multicolumn{10}{|l|}{ Serum folate $(\mathrm{nmol} / \mathrm{l})$} \\
\hline Mean & 28 & 1 & 36 & 1 & 8 & 4,12 & - & - & $<0.001$ \\
\hline Geometric mean & 23 & 21,24 & 30 & 28,32 & - & - & 1.31 & $1.19,1.45$ & $<0.001$ \\
\hline \multicolumn{10}{|c|}{ Erythrocyte folate $(\mathrm{nmol} / \mathrm{l})$} \\
\hline Mean & 794 & 21 & 1096 & 30 & 302 & 229,374 & - & - & $<0.001$ \\
\hline Geometric mean & 720 & 686,755 & 996 & 945,1049 & - & - & $1 \cdot 38$ & $1.29,1.48$ & $<0.001$ \\
\hline
\end{tabular}

SEM, standard error of the mean.

${ }^{*}$ Ratio of the geometric means of the 2008/09 New Zealand Adult Nutrition Survey and the 2011 Folate and Women's Health Survey. 
Table 3 Consumption of folic-acid-fortified or non-fortified bread and breakfast cereal, folic-acid-fortified yeast spread and folate supplements among participants in the 2011 Folate and Women's Health Survey

\begin{tabular}{|c|c|c|c|c|c|c|c|c|}
\hline & \multicolumn{2}{|c|}{ Consumers } & \multicolumn{2}{|c|}{ Any fortified } & \multicolumn{2}{|c|}{ All unfortified } & \multicolumn{2}{|c|}{$\begin{array}{l}\text { Unknown or combination o } \\
\text { unfortified and unknown }\end{array}$} \\
\hline & $n$ & $\%$ & $n$ & $\%$ & $n$ & $\%$ & $n$ & $\%$ \\
\hline Bread* & $266 \ddagger$ & 93 & $51 \S$ & 18 & 177 & 62 & 38 & 13 \\
\hline Breakfast cereal $^{\star}$ & $205 \ddagger$ & 72 & $116 \S$ & 41 & 74 & 26 & 15 & 5 \\
\hline Fortified yeast spread ${ }^{\star}$ & 152 & 53 & - & - & - & - & - & - \\
\hline Folate-containing supplement† & 77 & 27 & - & - & - & - & - & - \\
\hline
\end{tabular}

Values are based on 285 women who completed the dietary questionnaire.

${ }^{*}$ Consumption in the past week.

†Regular consumption.

fFor bread, consumed at least one slice of any bread in past week; for breakfast cereal, consumed at least one bowl of any breakfast cereal in past week. $\S$ For bread, consumed at least one slice of folic-acid-fortified bread in past week; for breakfast cereal, consumed at least one bowl of folic-acid-fortified breakfast cereal in past week.

Frequency of any breakfast cereal consumption, but not any bread consumption, predicted serum and erythrocyte folate concentrations. For every additional bowl of breakfast cereal consumed per week, the adjusted ratio of the geometric mean serum folate concentrations was 1.036 (95\% CI 1.012, 1.061, $P=0.003$ ) and the adjusted ratio of the geometric mean erythrocyte folate concentrations was $1 \cdot 031$ (95\% CI 1.013, 1.050, P=0.001; Table 5).

\section{Discussion}

Our results suggest that the mean serum folate concentration among women of childbearing age in New Zealand increased by $8 \mathrm{nmol} / \mathrm{l}$ after the introduction of a voluntary programme to fortify bread with folic acid. This is based on the differences between the present survey the 2011 Folate and Women's Health Survey - and the 2008/ 09 New Zealand Adult Nutrition Survey. Increased consumption of folic-acid-fortified bread is likely to have contributed to some of the difference because consumption of fortified bread was associated with $25 \%$ higher serum folate status. Increased consumption of folic-acid-fortified breakfast cereal probably also contributed to the difference in folate status between the two surveys. Breakfast cereal was an important predictor of serum folate status and the number of folic-acid-fortified breakfast cereals in New Zealand increased from forty-nine in 2008 to eighty-six in 2011; in 2011 this represented $53 \%$ of the total breakfast cereals in New Zealand ${ }^{(1)}$. Assuming total bread or breakfast cereal consumption did not change since 2008, the increase in folate status among women indicates a greater penetration of folic acid in the food supply. There is no evidence that the prevalence of folate supplement use increased in women of childbearing age between 2008 and 2011. Twenty-six per cent of female participants of childbearing age from the 2008/09 New Zealand Adult Nutrition Survey and 27\% of participants of the 2011 Folate and Women's Health Survey reported the consumption of a folate-containing supplement.
The dietary patterns of women in the 2011 Folate and Women's Health Survey appear representative of New Zealand women. A New Zealand-wide market survey estimated that $81 \%, 69 \%$ and $52 \%$ of New Zealand women aged 14 years or older had, in the past week, consumed bread, breakfast cereals and yeast extract spreads, respectively ${ }^{(15)}$. Although the 2011 Folate and Women's Health Survey encompassed a narrower age range, the results are comparable; we reported 93\%, 72\% and $53 \%$ of our participants had, in the past week, consumed bread, breakfast cereals and yeast extract spreads, respectively.

Based on the work of Daly et al. ${ }^{(16)}$ and Wald et al. ${ }^{(17)}$ the change in mean serum folate concentration from the 2008/09 New Zealand Adult Nutrition Survey to the 2011 Folate and Women's Health Survey can be used to predict the decline in neural tube defect rate. An 18\% reduction in the rate of neural tube defects would be predicted from an increase in serum folate concentration from $28 \mathrm{nmol} / \mathrm{l}$ (2008/09 New Zealand Adult Nutrition Survey) to $36 \mathrm{nmol} / 1$ (2011 Folate and Women's Health Survey).

Other countries have monitored blood folate status of the population before and after the introduction of a mandatory folic acid fortification programme. However, differences in the food fortification vehicles, target fortificant levels and food consumption patterns in different countries mean that the effect of mandatory fortification programmes on the folate status of a population will vary from country to country. Blood folate was measured in the Australian Health Survey 2011-2012 ${ }^{(18)}$, but it was not measured in national surveys that predate folic acid fortification of bread in 2009. Population-based surveys carried out in $\operatorname{Iran}^{(19)}$, Canada ${ }^{(20)}$, Costa Rica ${ }^{(21)}$, Chile ${ }^{(22,23)}$ and the USA ${ }^{(15)}$ have documented increases in folate status of women of childbearing age following the introduction of a mandatory folic acid fortification programme, but comparing the relative impact of the fortification programmes across the countries is further complicated by the lack of international standardisation and calibration of folate measurement. 
The serum and whole blood samples from the 2008/09 New Zealand Adult Nutrition Survey and the 2011 Folate and Women's Health Survey were analysed using the same microbiological assay in the same laboratory approximately two years apart. The mean value for the pooled sample, that was analysed 164 times in the 2008/09 New Zealand Adult Nutrition Survey and twenty-nine times in the 2011 Folate and Women's Health Survey, was the same $(19 \cdot 2 \mathrm{nmol} / \mathrm{l})$ in both surveys, suggesting excellent agreement of the laboratory analysis between the surveys. The NIST samples were analysed only four times in the 2011 Folate and Women's Health Survey; nevertheless, the values were consistently higher than those obtained in the 2008/09 New Zealand Adult Nutrition Survey. However, the difference was less than $2 \mathrm{nmol} / \mathrm{l}$ for all three levels of the NIST SRM. Thus, differences across time in laboratory measurements may explain only a small part of the difference in folate status between the 2008/09 New Zealand Adult Nutrition Survey and the 2011 Folate and Women's Health Survey.

There were some differences in the way blood samples were collected in the two surveys, which may affect the comparison of blood folate status. Fasting blood samples were collected in the 2011 Folate and Women's Health Survey whereas non-fasting samples were collected in the 2008/09 New Zealand Adult Nutrition Survey. Folic acid consumed before blood sampling can increase serum folate concentrations slightly. Öhrvik et $a l^{(24)}$ have shown an increase in serum folate of approximately $3 \mathrm{nmol} / \mathrm{l}$, in participants $(n 8)$ fed $200 \mu \mathrm{g}$ folic acid in fortified bread (a dose similar to what one might receive through consumption of a folic-acid-fortified food product), with the maximum change occurring 150 min post-ingestion. In the 2008/09 New Zealand Adult Nutrition Survey some participants probably consumed a fortified food product before the blood draw, although blood collection of these participants was likely to have occurred throughout the range of the postprandial time period. Thus, the effect on mean serum folate concentrations is likely to be quite small, probably about 1 to $2 \mathrm{nmol} / \mathrm{l}$. Any temporary postprandial increase in serum folate concentrations in the participants of the 2008/09 New Zealand Adult Nutrition Survey would tend to attenuate the magnitude of the true difference in serum folate status between the two surveys.

Both the 2008/09 New Zealand Adult Nutrition Survey and the 2011 Folate and Women's Health Survey used a random sampling technique. However, the response rate to the 2008/09 New Zealand Adult Nutrition Survey was slightly higher and there were slight differences in some participant characteristics between the surveys. More of the 2011 Folate and Women's Health Survey participants were of New Zealand European and other ethnicity, and resided in areas of less deprivation. These factors were associated with higher serum and erythrocyte folate status in univariate analyses of the entire 2008/09 New Zealand 
Table 5 Relationship between the frequency of consumption of bread or breakfast cereal and serum or erythrocyte folate in the 2011 Folate and Women's Health Survey

\begin{tabular}{lcccccc}
\hline Measurement & $\begin{array}{c}\text { Adjusted ratio per increment } \\
\text { of bread (slice per week) }\end{array}$ & $95 \% \mathrm{Cl}$ & $P$ value & $\begin{array}{c}\text { Adjusted ratio per increment of } \\
\text { breakfast cereal (bowl per week) } \dagger\end{array}$ & $95 \% \mathrm{Cl}$ & $P$ value \\
\hline Serum folate & 1.005 & $0.998,1.013$ & 0.18 & 1.036 & $1.012,1.061$ & 0.003 \\
Erythrocyte folate & 1.005 & $0.999,1.012$ & 0.08 & 1.031 & $1.013,1.050$ & 0.001 \\
\hline
\end{tabular}

*Values are per incremental difference in frequency of bread consumption; adjusted for use of folic-acid-containing supplements (yes/no), city of residence (Wellington or Dunedin) and bowls of breakfast cereal consumption.

†Values are per incremental difference in frequency of breakfast cereal consumption; adjusted for use of folic-acid-containing supplements (yes/no), city of residence (Wellington or Dunedin) and slices of bread consumption. For example, 1.036 can be interpreted as a $3.6 \%$ higher geometric mean serum folate concentration per incremental (one more bowl per week) difference in breakfast cereal consumption.

Adult Nutrition Survey data set (all $P<0.05$, data not shown) and therefore this may also explain a small part of the difference in folate status between the two surveys.

Although the four major bread manufacturers agreed to add folic acid to a third of their range, the New Zealand Association of Bakers estimated in 2011 that only $12.5 \%$ of loaves produced annually were fortified with folic acid ${ }^{(1)}$. The voluntary bread fortification strategy requested by the New Zealand Government was partially successful in increasing the number of folic-acid-fortified breads on the market; however, in the absence of mandatory regulation, the decisions on which products to fortify and by how much are ultimately made by the manufacturers. The latest report from New Zealand Baking Industry stated that in 2014, 19\% of New Zealand bread, by production volume, was fortified with folic acid ${ }^{(25)}$.

\section{Conclusion}

In conclusion, although the introduction of the voluntary bread fortification programme in New Zealand did not achieve broad coverage of women of childbearing age $18 \%$ of the participants reported consuming folic acid fortified bread in the past week - our results showed that women who consumed folic-acid-fortified bread had higher folate status than those who did not. The voluntary programme to fortify bread with folic acid undoubtedly contributed towards the increase in folate status of women of childbearing age in New Zealand, but the coincidental increase in the number of folic-acid-fortified breakfast cereals in the food supply makes it difficult to estimate how much of the increase in blood folate status of childbearing women can be attributed to fortification of bread. In 2012, the New Zealand Government announced that folic acid fortification of bread would remain voluntary in New Zealand and, together with the New Zealand Association of Bakers, developed a code of practice with a goal to fortify between $25 \%$ and $50 \%$, by production volume, of bread with folic acid. Our results show that a voluntary fortification can improve folate status, but they also are a strong reminder to public health authorities - of the obvious - that the extent of change is more difficult to predict and control than with a mandatory programme.
Given these results we believe that priority should be given to monitoring periodically the folate status of $\mathrm{New}$ Zealand women of childbearing age.

\section{Acknowledgements}

Financial support: The New Zealand Ministry for Primary Industries funded the 2011 Folate and Women's Health Survey. The New Zealand Ministry of Health funded the 2008/09 New Zealand Adult Nutrition Survey. The New Zealand Crown is the owner of the copyright for the 2008/ 09 New Zealand Adult Nutrition Survey data. The funder had no role in the design or conduct of the study, or in the collection, analysis and interpretation of the data, nor in the preparation, review or approval of the manuscript. Conflict of interest: The authors have no conflicts of interest to declare. Authorship: K.E.B., C.M.S., S.M.W., J.I.M., I.O., W.P., L.F. and R.C.B. designed the research; K.E.B. and C.A. conducted the research; S.M.W., K.E.B. and C.M.S. performed the statistical analysis; K.E.B. and C.M.S. wrote the paper; C.M.S. had primary responsibility for the final content; W.P. was the Nutrition Director of the 2008/09 New Zealand Adult Nutrition Survey; all authors read and approved the final manuscript. Ethics of buman subject participation: The University of Otago's human ethics committee approved the 2011 Folate and Women's Health Survey.

\section{References}

1. Ministry for Primary Industries (2012) Voluntary Folic Acid Fortification: Monitoring and Evaluation Report. Wellington: Ministry for Primary Industries.

2. Food Standards Australia New Zealand (2007) Australia New Zealand Food Standards Code - Amendment No. 93. Canberra: FSANZ.

3. Food Standards Australia New Zealand (2007) First Review Report - Proposal P295: Consideration of Mandatory Fortification with Folic Acid. Canberra: FSANZ.

4. Ministry for Primary Industries (2012) The Future of Folic Acid Fortification of Bread in New Zealand. Wellington: Ministry for Primary Industries.

5. Wilkinson K (2009) Government defers folic acid fortification. http://www.beehive.govt.nz/release/government-defersfolic-acid-fortification (accessed December 2012). 
6. Bradbury KE, Williams SM, Mann JI et al. (2012) Estimation of serum and erythrocyte folate concentrations in the New Zealand adult population within a background of voluntary folic fcid fortification. J Nutr 144, 68-74.

7. Bradbury KE, Williams SM, Green TJ et al. (2012) Differences in erythrocyte folate concentrations in older adults reached steady-state within one year in a two-year, controlled, $1 \mathrm{mg} / \mathrm{d}$ folate supplementation trial. J Nutr 142, 1633-1637.

8. University of Otago \& Ministry of Health (2011) Methodology Report for the 2008/09 New Zealand Adult Nutrition Survey. Wellington: Ministry of Health.

9. Statistics New Zealand (2007) 2006 Census data: Tables about New Zeland. http://www.stats.govt.nz/Census/2006 CensusHomePage/Tables/AboutAPlace/SnapShot.aspx?id= 9999999\&type $=$ region (accessed February 2012).

10. Dillman D, Smyth J \& Christian L (2009) Internet, Mail, and Mixed-Mode Surveys: The Tailored Design Method, 3rd ed. Hoboken, NJ: John Wiley \& Sons, Inc.

11. O'Broin S \& Kelleher B (1992) Microbiological assay on microtitre plates of folate in serum and red cells. $J$ Clin Pathol 45, 344-347.

12. Herbert V (1967) Biochemical and hematologic lesions in folic acid deficiency. Am J Clin Nutr 20, 562-572.

13. Institute of Medicine (2000) Dietary Reference Intakes for Thiamin, Riboflavin, Niacin, Vitamin $B_{6}$, Folate, Vitamin $B_{12}$, Pantothenic Acid, Biotin, and Choline. Washington, DC: The National Academies Press.

14. Gibson R (2005) Assessment of folate and vitamin $B_{12}$ status. In Principles of Nutritional Assessment, 2nd ed., pp. 595-640. Oxford: Oxford University Press.

15. Pfeiffer CM, Hughes JP, Lacher DA et al. (2012) Estimation of trends in serum and RBC folate in the US population from pre- to postfortification using assay-adjusted data from the NHANES 1988-2010. J Nutr 142, 886-893.
16. Daly LE, Kirke PN, Molloy A et al. (1995) Folate levels and neural tube defects. Implications for prevention. JAMA $\mathbf{2 7 4}$, 1698-1702.

17. Wald N, Law M, Morris J \& Wald D (2001) Quantifying the effect of folic acid. Lancet 358, 2069-2073.

18. Australian Bureau of Statistics (2014) Australian Health Survey: Biomedical Results for Nutrients, 2011-12. Canberra: ABS; available at http://www.abs.gov.au/AUSSTATS/ abs@.nsf/DetailsPage/4364.0.55.0062011-12?OpenDocument

19. Abdollahi Z, Elmadfa I, Djazayery A et al. (2011) Efficacy of flour fortification with folic acid in women of childbearing age in Iran. Ann Nutr Metab 58, 188-196.

20. Liu S, West R, Randell E et al. (2004) A comprehensive evaluation of food fortification with folic acid for the primary prevention of neural tube defects. BMC Pregnancy Childbirth 4, 20.

21. Chen LT \& Rivera MA (2004) The Costa Rican experience: reduction of neural tube defects following food fortification programs. Nutr Rev 62, 6 Pt 2, S40-S43.

22. Hertrampf E, Cortes F, Erickson JD et al. (2003) Consumption of folic acid-fortified bread improves folate status in women of reproductive age in Chile. J Nutr $\mathbf{1 3 3}$, 3166-3169.

23. Hertrampf E \& Cortes F (2004) Folic acid fortification of wheat flour: Chile. Nutr Rev 62, 6 Pt 2, S44-S48.

24. Öhrvik V, Öhrvik H, Tallkvist J et al. (2010) Folates in bread: retention during bread-making and in vitro bioaccessibility. Eur J Nutr 49, 1365-1372.

25. Baking Industry Research Trust (2015) Voluntary fortification of bread with folic acid. Annual Report 2014. http://www. bakeinfo.co.nz/files/file/620/Voluntary\%20fortification\%20of\% 20bread\%20with\%20folic\%20acid\%20Annual\%20Report\% 202014\%20\%20May\%202015\%20Final.pdf (accessed August 2015). 